\title{
Proportional Reasoning and Related Concepts: Analysis of Gaps and Understandings of Middle Grade Students
}

\author{
Bobby Ojose \\ Department of Teacher Education, Youngstown State University, One University Plaza, USA
}

Copyright $@ 2015$ Horizon Research Publishing All rights reserved.

\begin{abstract}
This study investigated proportional reasoning and the related concepts of decimal, percent, and ratio. In particular, the research focused on analyzing the gaps and understandings that grades 6,7 , and 8 students have and advanced factors for such gaps and understandings. The study employed a mixed method approach in which quantitative data was collected and analyzed in the first phase. The hypothesis that differences in mean performance of students on the test among grades 6,7 , and 8 would be statistically significant was not supported by the data. The second phase involved collection of qualitative data, specifically interviews and documents observation. The interview data revealed that several factors relating to the learner, task, and strategy were responsible for the gaps and understandings. Implication for planning, instruction, and assessment is discussed.
\end{abstract}

Keywords Proportional Reasoning, Conceptual Understanding, Achievement, Gaps Analysis, Proportion, Ratios, Percent

\section{Introduction}

The National Council of Teachers of Mathematics (NCTM) lists proportional reasoning as a cardinal concept to be grasped in the middle grades. According to NCTM Curriculum and Evaluation Standards [1], "The ability to reason proportionally develops in students throughout grades 5-8. It is of such great importance that it merits whatever time and effort that must be expended to assure its careful development." (p. 82). This position is equally elucidated by the present Common Core States Standards (CCSS). For example, the CCSS want students in grade 6 to understand ratio concepts and use ratio reasoning to solve problems. In grade 7 , the CCSS want instructional time focused on the critical area of developing understanding of and applying proportional relationships. CCSSI [2] states, "Student extend their understanding of ratios and develop understanding of proportionality to solve single- and multi-step problems...solve a wide variety of percent problems, including those involving discounts, interest, taxes, tips, and percent increase or decrease." (p. 46).

Proportional reasoning is a concept in the middle grades that demands researchers' attention because of its centrality to the study of mathematics. The concept also enhances the learning of further mathematics. Heinz \& Sterba-Boatwright [3] stated, "Proportional reasoning is at the core of so many important concepts in mathematics and science, including similarity, relative growth and size, dilations, scaling, pi, constant rate of change, slope, rates, percent, trig ratios, probability, relative frequency, density, and direct and inverse variations." (p. 528). Consequently, no amount of research devoted to this area of mathematics education can be deemed disproportionate.

This study was designed to investigate the knowledge of students in grades 6 through 8 in proportional reasoning and related concepts of decimal multiplication, percent, and ratios. Specifically, the study explored the gaps and understandings that students in grades 6,7 and 8 possess in this area of mathematics and explored factors that could be responsible. This study is unique because both quantitative and qualitative data were used to analyze the phenomenon. It needs to be mentioned that there is limited literature on gaps analysis involving proportional reasoning. For instance, the factors that account for the knowledge that students possess are not readily seen in past studies. The present study addressed this deficiency of previous studies by seeking to know why such gaps exist.

Also, previous studies related to proportional reasoning have been quite heavy on explicating lack of understanding to the detriment of highlighting what students know and are able to do. So in addition to analyzing gaps, the study achieved an exquisite purpose of honing in on the understanding that students have with the concept of proportional reasoning. Also, instead of singular analysis of proportional reasoning, those concepts that are related and would have been learned prior are also analyzed in the study. Consequently, the related concepts of decimal multiplication, percent, and ratio are part of the present study.

A significant amount of work has been done at the elementary, secondary, and college levels regarding proportional reasoning and the related concepts (e.g., ratio, 
percent and proportion). Tourniaire [4] investigated young students in grades 3, 4, and 5 in proportion. The study concluded that based on the success rate, young students have some understanding of the concept of proportion and that familiarity with the use of ratios in context, the presence of a mixture, and the use of manipulatives were context variables that influenced performance. Mixed results have however been found in studies that seek to find out about the knowledge of proportional reasoning at the secondary and college levels. Also, evidence exists that "A large segment of our society never acquires fluency in proportional reasoning." (Hoffer, [5], p. 285).

At the secondary level, findings have shown lack of understanding with the concept of proportional reasoning. Singh [6] investigated the concepts of ratio and proportion constructed by grade 9 students' proportional reasoning schemes and procedures on three types of tasks: missing value, numerical comparison, and qualitative reasoning. Results indicate that only a small percentage of students who did well on a national exam were able to solve complex proportional problems and the grades obtained were not indicative of their knowledge of ratio and proportion. This finding is in line with other studies which concurs that proportional reasoning and the related concepts are "difficult concepts that present a challenge to many students." (Ben-Chaim, Fey, Fitzgerald, Benetto \& Miller, [7]; Lo \& Watanabe, [8]).

At the college level, the story is similar. Although instruction in proportions generally begins in the middle school years, proportional reasoning remains problematic for many college students (Lawton, [9]). The finding of Lawton's study indicate that college students more readily solve proportion problems if the contents of the items in the problem are relatively distinct from one another. This implies that college students lack conceptual understanding of proportional reasoning.

\section{Guiding Frameworks}

Two frameworks that guided this study are the information processing model and the metacognitive awareness theory. Both of these frameworks are grounded in and are under the canopy of the cognitive learning theory. According to Eggen \& Kauchak [10], cognitive theories help us better understand the complexities of learning mathematics, including the role that motivation, beliefs, expectations, and strategies play in determining how students learn." (p. 386).

The information processing model wants students to exhibit the knowledge they possess. It also explicates the ability of students to explain their thought process. The theory was at various times elaborated on (e.g., Atkinson \& Shiffrin, [11]; Gagne, [12]; Anderson, [13]). The model consists of perception, encoding, storage, and retrieval. Gagne [12] translated the information processing model into an instructional model called "phases of learning." An example would be the internal process in the child to retrieve working memory as the teacher asks for recall of previously learned information.

The metacognitive awareness theory is influenced by variables associated with learners, tasks, and strategies (Duell, [14], cited in Schunk, [15], p. 193). According to Flavell [16], “... metacognition is loosely defined as any knowledge or cognitive activity that takes as its object, or regulates, any aspect of the cognitive enterprise ...It is called metacognition because its core meaning is 'cognition about cognition.' Metacognitive skills are believed to play an important role in many types of cognitive activity... including perception, attention, memory, and problem solving" (Cited in Schunk, [15], p. 192). In a nutshell, metacognition is the student's ability to control their cognitive processes.

\section{Hypothesis}

The first phase of the study is the quantitative part where the data obtained from the test administered to students was analyzed using statistical procedures. The two hypotheses that guided the quantitative phase are as follows:

1. The alternate hypothesis was assumed in the means comparison. Symbolically, I anticipated $\mathrm{H}_{\mathrm{A}}: \mathrm{M}_{8}>\mathrm{M}_{7}>\mathrm{M}_{6}$. This implies that the mean generated from each of the test questions for grade 8 would be higher than that of grades 7 and 6. Likewise, the mean of grade 7 would be higher than that of grade 6 .

2. A second hypothesis was that the differences in the means would be statistically significant. My reason for posing the above hypotheses is obvious - students in higher grades should intuitively perform better than students in lower grades in mathematical concepts. This reasoning is supported by Tourniaire [4] who suggests that "Performance improves with age, up to adulthood." (p. 401).

\section{Research Questions}

Based on the outcome and results of the quantitative phase of the study, further analysis was done by interviewing the teachers and selected students to shed more light on the quantitative data. Therefore the following research questions guided the qualitative phase of the study:

1. What understanding do students possess of the concept of proportional reasoning and the related concepts?

2. What factors account for the understanding or lack of understanding (gaps) exhibited by students?

\section{Methodology}

\section{Participants}

Participants were $6^{\text {th }}-, 7^{\text {th }}$ - and $8^{\text {th }}$ - grade students in a suburban northeastern city of the United States. The middle 
school has a few number of migratory students and students from low socioeconomic backgrounds. There were a total of 114 students who participated in the study: 35 were grade 6 ; 43 were grade 7 ; and 36 were grade 8 . Sixty four participants were females and 50 were males ranging from 12 years to 14 years and 5 months. In addition, the three teachers for grade 6 (Mr. A), grade 7 (Mr. B), and grade 8 (Mr. C) were also part of the qualitative phase of the study.

\section{Instrumentation}

The test administered to students was constructed by the researcher. As indicated, the questions were those that relates to proportions and proportional reasoning. Hence there was a question each in decimal multiplication, percent, ratio, proportion, and proportional reasoning. In constructing the questions, I had in mind that each solution set should somehow result to thinking proportionally. Also, the test was constructed in such a way that the answer to all problems was the same. The rationale for this was to prompt students into thinking about how the concepts may be related or not related. It should be noted that the concepts of proportion and proportional reasoning are same in the context of mathematical structure and they are taught in the same time frame in any given school year. However, I distinguished between them in this study. While the proportion problem was used to find out understanding related to missing value, the proportional reasoning problem is contextual and was meant for students to show understanding of application. The point being made here is that the concepts are not necessarily different; even though they seem to be referred to as two different things in this study.

\section{Procedure}

There were two steps involved in the data collection process. First, the quantitative data was obtained by administering the constructed test to students in grades 6,7 , and 8 . The teachers administered the test during the regular class period. Students were to answer all five questions and show their work. To accommodate slower test takers, I instructed the teachers to give all students enough time to complete the test. Even though the questions can conveniently be completed in a class period, I suggested that teachers allow students to complete the test in a later day if they were unable finish in one class period. Feedback from the teachers indicated that all students completed the test and that time was not an issue. Each of the five questions was graded on a 4-point scale.

After grading and initial analysis of the descriptive statistics, two students who got all questions right from each grade level were selected and scheduled for interviews. In addition, their teachers (Mr. A, Mr. B, and Mr. C) were also scheduled to be interviewed. The purpose of the interviews was to find out more about the understanding that students has of proportional reasoning and the related concepts. This was to further explore the gaps and understandings exhibited by students. The interviews were conducted by the researcher and two assigned research assistants during a spring semester. The participants (teachers and students) were selected as a result of convenience. The teachers were the cooperating teachers to whom my preclinical students were assigned. Consequently, I was in these classes at least once a week for the semester.

\section{Data Analysis}

As stated earlier, both quantitative and qualitative data were collected for the study. Appropriately, a mixed method procedure was employed in analyzing the data. This was imperative because the purpose of the investigation which was to find out about understandings and to analyze factors responsible for a phenomenon can hardly be captured in one kind of data. According to Gay, Mills \& Airasian [17], "The purpose of mixed methods research is to build on the synergy and strength that exists between quantitative and qualitative research methods to understand a phenomenon more fully than possible using either quantitative or qualitative alone." (p. 481). Specifically, the model used with this study was the exploratory sequential design which begins with quantitative data collection and analysis and then followed up with qualitative data collection and analysis. According to Creswell [18], "The rationale for exploratory sequential design is that the quantitative data and results provide a general picture of the research problem; more analysis, specifically through qualitative data collection is needed to refine, extend, or explain the general picture." (542).

In the quantitative phase, the collected data (test scores of students) was entered into the Statistical Program for the Social Sciences (SPSS) program. Specifically, one-way Analysis of Variance (ANOVA) was used to compare the means and test the hypotheses. The means, standard deviations, degree of freedom and the F-ratio were extracted appropriately and analyzed. For the qualitative data, interviews were tape recorded and transcribed. The tests for each of the selected student to be interviewed were perused prior to the interviews. Students were asked pertinent questions that would help in understanding what they know or do not know about proportional reasoning.

\section{Findings}

Quantitative Data: The following data was obtained from the test given to participants in the study.

Table 1. Data from Question A: .05 x $80=$

\begin{tabular}{|c|c|c|c|}
\hline & Total Points & Mean & SD \\
\hline Grade 6 & 86 & 2.46 & 0.878 \\
\hline Grade 7 & 122 & 2.84 & 0.837 \\
\hline Grade 8 & 93 & 2.58 & 1.107 \\
\hline
\end{tabular}

QA: In the multiplication of decimal problem, results showed that the mean score of students in grade 7 was more than those in grade 8 and this contradicts the initial 
hypothesis. Here $M_{7}>M_{8}>M_{6}$.

Table 2. Data from Question B: What is $5 \%$ of 80 ?

\begin{tabular}{|c|c|c|c|}
\hline & Total Points & Mean & SD \\
\hline Grade 6 & 72 & 2.06 & 0.708 \\
\hline Grade 7 & 83 & 1.93 & 1.035 \\
\hline Grade 8 & 133 & 3.69 & 0.845 \\
\hline
\end{tabular}

QB: In the percent problem, the initial hypothesis was not upheld. The mean score of grade 8 was greater than that of grades 7 and 6 . However, the mean score of grade 6 was greater than grade 7 . Here $M_{8}>M_{6}>M_{7}$.

Table 3. Data from Question C: Find the missing number: 5:100 = ? : 80

\begin{tabular}{|c|c|c|c|}
\hline & Total Points & Mean & SD \\
\hline Grade 6 & 76 & 2.17 & 1.060 \\
\hline Grade 7 & 102 & 2.37 & 1.045 \\
\hline Grade 8 & 155 & 4.30 & 0.599 \\
\hline
\end{tabular}

QC: In the ratio problem, the hypothesis was supported. The mean score of grade 8 was greater than that of grade 7 and 6. Here $\mathrm{M}_{8}>\mathrm{M}_{7}>\mathrm{M}_{6}$.

Table 4. Data from Question D: Solve for $\mathrm{x}: 5 / 100=\mathrm{x} / 80$

\begin{tabular}{|c|c|c|c|}
\hline & Total Points & Mean & SD \\
\hline Grade 6 & 73 & 2.08 & 0.993 \\
\hline Grade 7 & 95 & 2.21 & 1.127 \\
\hline Grade 8 & 124 & 3.44 & 1.042 \\
\hline
\end{tabular}

QD: In the proportion problem, the hypothesis was supported because grade 8 has a mean score higher than grades 7 and 6. Here $M_{8}>M_{7}>M_{6}$.

Table 5. Data from Question E: If 5 quarters can buy 100 candies, how many quarters can buy 80 candies?

\begin{tabular}{|c|c|c|c|}
\hline & Total Points & Mean & SD \\
\hline Grade 6 & 92 & 2.62 & 0.867 \\
\hline Grade 7 & 119 & 2.96 & 0.971 \\
\hline Grade 8 & 97 & 2.69 & 1.356 \\
\hline
\end{tabular}

QE: In the proportional reasoning problem, the mean score of students in grade 7 was higher than grade 8 . This is at variance with the initial hypothesis which premised that higher grades will perform better than lower grades. Here $\mathrm{M}_{7}>\mathrm{M}_{8}>\mathrm{M}_{6}$.

Now moving on to the second hypothesis of the study. I did hypothesize that differences in the means of grades 6,7 , and 8 would be statistically significant. Tables 6 and 7 below provide the answer to this hypothesis:

Following test administration, no significant differences were found between and among students' mean scores of the three grade levels on the entire test. As indicated on the output tables, the mean score of grade 6 was 12.43 with SD of 5.141; the mean score of grade 7 was 12.44 with SD of 4.061; and the mean score of grade 8 was 14.25 with SD of 3.879. This is not statistically significant $(\mathrm{F}(2,111)=2.124$, $\mathrm{p}>.05)$. This finding contradicts my hypothesis which claimed that the differences in the means of the three grade levels would be statistically significant.

\section{Qualitative Phase}

To answer the research questions posed at the outset, the first thing I did was to peruse the scored test of students with the aim of identifying some solutions that are non-routine. This meant looking for students' work that does not use pure algorithmic methods. To my disappointment, all of the solutions by students in all grades used standard algorithms. However, when I met with students to conduct the interviews and made them use a different method to solve the proportional reasoning problem, a different outcome manifested. The students were able to use non-routine methods- diagrams, tables, words, etc. to show their work. The following questions were asked each student during the interview: 1. Look at your work again. You got the same answer for all the questions. In your opinion why is this so? 2 . What similarities or differences can you see that exist between and among all five problems? 3. For the last question (the proportional reasoning problem), can you show a different method of solving the problem? In the third interview question, students were encouraged to represent their thoughts using any form - drawing, words, tables, etc.

Table 6. Descriptive Statistics

\begin{tabular}{|c|c|c|c|c|c|c|c|c|}
\hline & \multirow{2}{*}{$\mathrm{N}$} & \multirow{2}{*}{ Mean } & \multirow{2}{*}{ Std. Deviation } & \multirow{2}{*}{ Std. Error } & \multicolumn{2}{|c|}{$95 \%$ Confidence Interval for Mean } & \multirow{2}{*}{ Minimum } & \multirow{2}{*}{ Maximum } \\
\cline { 5 - 7 } & & & & & Lower Bound & Upper Bound & & \\
\hline 1 & 35 & 12.43 & 5.141 & .869 & 10.66 & 14.19 & 5 & 20 \\
\hline 2 & 43 & 12.44 & 4.061 & .619 & 11.19 & 13.69 & 5 & 20 \\
\hline 3 & 36 & 14.25 & 3.879 & .647 & 12.94 & 15.56 & 8 & 20 \\
\hline Total & 114 & 13.01 & 4.411 & .413 & 12.19 & 13.83 & 5 & 20 \\
\hline
\end{tabular}

Table 7. One-way ANOVA for the test $\mathrm{H}_{\mathrm{A}}: \mathrm{M}_{8}>\mathrm{M}_{7}>\mathrm{M}_{6}$

\begin{tabular}{|c|c|c|c|c|c|}
\hline & Sum of Squares & df & Mean Square & F & Sig. \\
\hline Between Groups & 81.065 & 2 & 40.533 & 2.124 & P $>.05^{*}$ \\
\hline Within Groups & 2117.926 & 111 & 19.080 & & \\
\hline Total & 2198.991 & 113 & & & \\
\hline
\end{tabular}

\footnotetext{
*Hypothesis tested at the .05 level.
} 
For interview questions 1 and 2, the aim was to see if students could recognize that the problems are in fact related and can be solved using common sense, even without computation. As would be expected, there were hits and misses which will be discussed next. But first I should mention that some students showed novel ways of solving the problems. For example, one grade 8 student demonstrated conceptual understanding by using symbols and algebraic manipulation as shown in Figure 1 below:

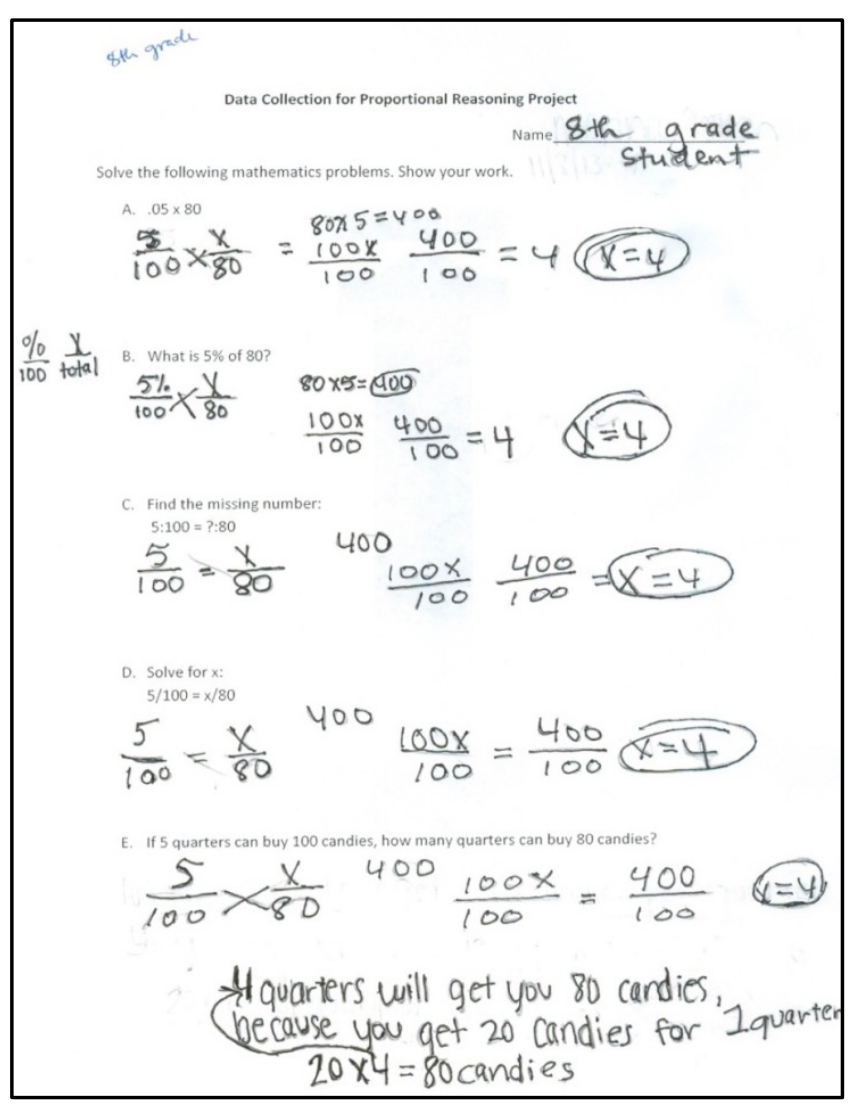

Figure 1. Solution Sets of a Grade 8 Student

The student set up a proportion and uses cross multiplication method to find the value of $\mathrm{x}$ in all of the problems. The significance of this is that the student was able to use the same reasoning to solve concepts of decimal multiplication, percent, ratio, and proportion.

The gaps exhibited in the proportional reasoning concept was evident in the quantitative data as well as the information revealed by the interview data and students' work. Recall that the quantitative data has the grade 8 students recording a mean of 2.69 (maximum points $=4$ ) in the proportional reasoning question. Gap was also evident when students were asked to explain the similarities and or differences with and among the concepts. The purpose of the similarities and differences interview question was to find out the misconceptions that students might have with the concepts. It was found that even though a student might have the correct answer to a problem, gap in understanding may still exist as exhibited by students' explanation. For example, the grade 6 and 7 students basically stated that they cannot fathom any differences or similarities among the concepts. The grade 6 student stated: "I don't know if they are similar or different, it's just that I can solve the problems." One of the grade 8 student stated: "There is 80 and 5 in every single problem, so it has to deal with 4 and you use equation to solve; and I can see they are different because they are different topics of decimal, ratio, and percent." At this point, I asked a further question: "But can decimal be percent and ratio be proportion, etc.? The grade 8 student answered: "Not necessarily because they are not the same math topic." At minimum, the expectation was for students to explain how the different concepts of decimal, percent, ratio, and proportion are connected or related.

The third interview question wants students to show an alternative method of solving the proportional reasoning problem. The work of all three grade levels is shown below. It needs to be highlighted that the three pieces of work analyzed are the best and represents the highest level of organized thinking by a student from each grade level.

Grade 6 Student. The student drew a picture to illustrate the thought process in solving the proportional reasoning problem as shown in Figure 2 below:

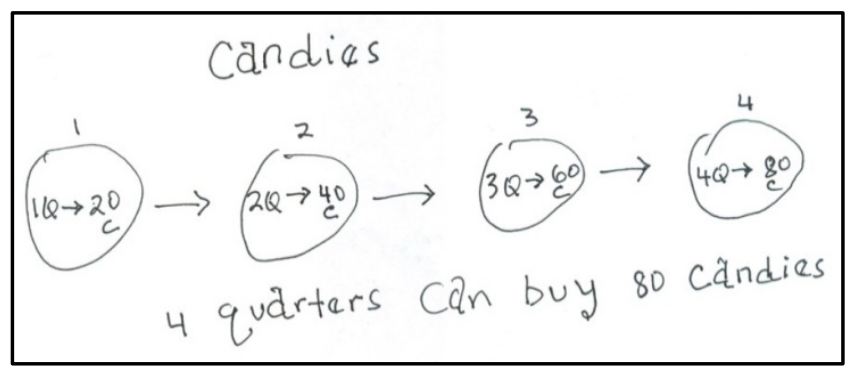

Figure 2. Sixth Grade Solution to the Proportional Reasoning Problem.

As shown above, the grade 6 student was able to arrive at the correct answer by a different method of drawing a picture. The student figured out that one quarter will buy 20 candies and then continue a pattern of circles that led to the correct answer. Grade 7 Student. The student used a table to illustrate his thinking as shown in Figure 3 below:

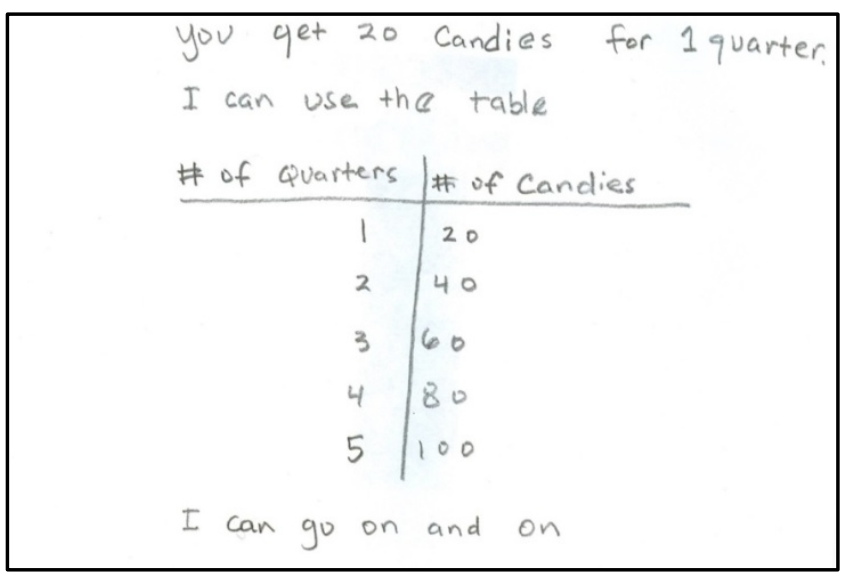

Figure 3. Seventh Grade Solution to the Proportional Reasoning Problem.

As shown above, this student preferred using a table as a 
different solution path to the problem. The student found that "One quarter would be 20 candies, 2 quarters would be 40 candies, 3 quarters would be 60 candies and on and on." When I demanded to know what "On and on" mean, the student said: "If I know any number of quarters, I can figure out the number of candies I can buy."

Grade 8 Student. The student used counter argument and analysis to answer the question. She stated: "Our teacher says that proportion is stating that two ratios are equal. I see that $5 / 100=4 / 80=3 / 60=2 / 40$ are proportions. If we take any pair and do the cross products, we would get the same thing:

$5 / 100=4 / 80$,

Then $5 \times 80=4 \times 100$

This means $400=400$ (true statement)
Also, $4 / 80=3 / 60$

Then $3 \times 80=4 \times 60$

This means $240=240$ (true statement)

Now this is true of any pair of proportion taken. But if I was to get a different answer, say 3 instead of 4, my proportion would look like this:

$5 / 100=3 / 80$

This would be $3 \times 100=5 \times 80$ which is $300=400$ and would be incorrect"

Although I had to ask clarifying questions to help me better understand the thinking of this student, the bottom line however is that the underlying concept of proportional reasoning was demonstrated by the student. The student basically used trial and error method to see if the answer (4) to the problem was reasonable.

Table 8. Matrix Organizing Teacher Interview Data

\begin{tabular}{|c|c|c|c|}
\hline Question & Teacher & Exemplar Quote & Theme That Emerged \\
\hline \multirow{3}{*}{ Q1 } & Mr. A & $\begin{array}{c}\text { "The only concepts I have formally taught to my students are decimals and ratios; we are yet } \\
\text { to do proportion, percent, and proportional reasoning." }\end{array}$ & $\begin{array}{l}\text { Proportional reasoning } \\
\text { concept not yet taught }\end{array}$ \\
\hline & Mr. B & $\begin{array}{c}\text { "All concepts except proportional reasoning have been taught and I intend to teach it in a } \\
\text { week or two." }\end{array}$ & $\begin{array}{l}\text { Proportional reasoning } \\
\text { concept not yet taught }\end{array}$ \\
\hline & Mr. C & $\begin{array}{l}\text { "I did teach all these concepts in } 6^{\text {th }} \text { and } 7^{\text {th }} \text { grade. All I am doing now is periodically } \\
\text { reviewing the concepts if they are needed in understanding any topics that I am teaching." }\end{array}$ & $\begin{array}{l}\text { Proportional reasoning } \\
\text { concept already taught. }\end{array}$ \\
\hline \multirow[t]{3}{*}{ Q2 } & Mr. A & $\begin{array}{l}\text { "There is a program that we use in the } 6^{\text {th }} \text { grade and it is provided by the district. The program } \\
\text { is restrictive because you just basically teach it the way it is set up. It is technology-based and } \\
\text { the lesson plans are already formatted. We just teach it. We have CDs for all the lessons. For } \\
\text { example, if I want to teach my students ratios, I would project the material to the screen. } \\
\text { There is the problem of the day, sequence of examples related to the topic and I have students } \\
\text { copy the notes while I explain the concept; then they do the checking for understanding } \\
\text { problem; then they do the independent practice and then classwork." }\end{array}$ & $\begin{array}{l}\text { Prescribed method of } \\
\text { teaching }\end{array}$ \\
\hline & Mr. B & $\begin{array}{l}\text { "I use various methods depending on the topic being taught. I could use lecture method or } \\
\text { group work. For example, when I taught percent, I gave students an activity where in groups, } \\
\text { they decided on what to buy or which store to buy based on given information." }\end{array}$ & Lectures/ Group work \\
\hline & Mr. C & $\begin{array}{l}\text { "I basically pose a problem and have students struggle to solve it. If necessary, I give input to } \\
\text { help them solve it. I put the students at the center of the learning. My job is more of guiding." }\end{array}$ & $\begin{array}{l}\text { Learner-centered } \\
\text { instruction }\end{array}$ \\
\hline \multirow{3}{*}{ Q3 } & Mr. A & $\begin{array}{l}\text { "I am surprised that my students got the proportional reasoning problem right even without } \\
\text { teaching it. I really don't know how but I think because they probably related to the question } \\
\text { as it is a real-life situation problem. For those that performed poorly, I think two reasons } \\
\text { might be responsible. First, I have not covered all the topics and second, there is the problem } \\
\text { of motivation with my students. It is difficult to get them to do some things. So I think that } \\
\text { even though some of them might know how to solve the problems, they just wouldn't do it. I } \\
\text { think I need to work on some ways to motivate my students to do their best at all times." }\end{array}$ & $\begin{array}{l}\text { Real-life related task } \\
\text { Task Variable } \\
\text { Motivation } \\
\text { Leaner Variable }\end{array}$ \\
\hline & Mr. B & $\begin{array}{l}\text { "My students find it hard to remember past stuff. After learning it, they just think it is not } \\
\text { relevant anymore. Some also hold negative view of math; that is, math is difficult and do not } \\
\text { even try to solve a problem if it is challenging. Those that did well are those that perseveres } \\
\text { and I think most of those students are good problem solvers anyway." }\end{array}$ & $\begin{array}{c}\text { Remembering } \\
\text { Learner Variable } \\
\text { Negative Perception about } \\
\text { Math } \\
\text { Learner Variable }\end{array}$ \\
\hline & Mr. C & $\begin{array}{l}\text { "Inability to apply what was learned is a problem that I think those that did not do well have. } \\
\text { They easily forget also. Those students usually do not take their work very seriously. For } \\
\text { those that did well, I think that they simply remember their decimals, percent, and ratio partly } \\
\text { because we use them and refer to them daily in problem solving. For example, in our warm } \\
\text { up exercises, we use those concepts at least } 5 \text { minutes per day. I also think that those that did } \\
\text { well have better strategies in tackling math problems. It is almost certain to have the two } \\
\text { extremes in any class; I mean the good problem solvers and the not so good." }\end{array}$ & $\begin{array}{c}\text { Application of previous } \\
\text { knowledge } \\
\text { Strategy Variable } \\
\text { Remembering/forgetting } \\
\text { Learner Variable } \\
\text { Effective strategies for } \\
\text { solving problems } \\
\text { Strategy Variable }\end{array}$ \\
\hline
\end{tabular}


Teacher Interviews: The interview protocol was handed to teachers prior to the actual interview day. The purpose was to apprise them of the expectation and to obtain as much information as possible in the areas of curriculum and instruction. The protocol was also intended to understand the perception of teachers about students' knowledge of the concepts. It should be mentioned that the school practices looping as placement strategy. Powell [19] describes looping as the "continuous year-to-year instructional planning involving the same team of students and teachers and students typically move to the next grade with the current team" (p. 159). Students at this school move with their mathematics teachers to the next grade. This implies that Mr. $\mathrm{C}$, the $8^{\text {th }}$ grade teacher has had his students since sixth grade.

The following three questions were asked: 1 . Of the concepts of decimal multiplication, percent, ratio, proportion, and proportional reasoning, which one(s) have you taught and which one(s) have you not taught? 2. What instructional strategies do you use in general? Or do you use specific strategies with different math concepts/topics? 3. What factors would you advance as the reasons why some students did well and others did poorly on the test? The metacognitive awareness framework was employed in organizing the factors elucidated by the teachers. As listed in the guiding frameworks section, these include: Learner variable, task variable, and strategy variable.

Note the following regarding Table 8: Mr. A is the sixth grade teacher, $\mathrm{Mr}$. B is the seventh grade teacher, and Mr. C is the eighth grade teacher. Also, Q1, Q2, and Q3 represents interview questions 1,2 , and 3 respectively.

As pointed out earlier, I had the opportunity of visiting the classrooms of teachers in the study and informally observed what goes on with teaching in the classes. In all of my visits, not much hands-on activities was observed. The grade 7 teacher did engage in some hands-on and group activities from time to time. However, lecture was the major instructional strategy that the teachers used throughout the period of my visit.

\section{Discussion and Conclusions}

This purpose of this study was to investigate the gaps and understandings of grades 6,7 , and 8 students in the concept of proportional reasoning and other related concepts of decimal, percent, and ratio and advance possible factors. The study involved two phases of quantitative and qualitative data collection and analysis. The first hypothesis used to analyze the quantitative data was that the mean of students in grade 8 would be higher than that of grades 7 and 6 . Similarly, it is assumed that the mean of students in grade 7 would be higher than that of grade 6 . The data however did not support this hypothesis because in the decimal multiplication problem, the mean of grade 7 students was higher than that of grade 8. Likewise, in the percent problem, the mean of students in grade 6 was higher than that of grade 7. In the proportional reasoning problem, performance was virtually same for all grade levels. The second hypothesis which is a corollary of the first was that differences in means would be statistically significant. Again, this hypothesis was not supported by the data. The data reveals that the higher the grade does not necessarily mean higher performance in mathematical concepts as it relate to proportional reasoning. Put differently, age does not necessarily account for performance in proportional reasoning and its related concepts because as the data show, grades 6 and 7 were able to answer the proportional reasoning question even without being taught the concept. This finding is in line with previous studies (Lo \& Watanabe, [8]; Schorn, [20]; Van den Brink \& Streefland, [21]) whose analyses demonstrate that "ratio and proportion tasks are accessible to younger students." This is also the position of Tourniaire [4] who concluded that young children have some idea of the concept of proportion and "can solve simple (structurally and conceptually) proportion problems."

In the qualitative phase, two research questions guided the study. The first question concerns the knowledge possessed by students in proportional reasoning and the related concepts. Analysis of student tests and interviews indicate that all grade levels could possess conceptual understanding of the concept of proportional even without being taught the concept. This implies that both the quantitative and qualitative data paints the same picture. Note again that students in grades 6 and 7 in this study have not been taught the proportion and proportional reasoning concepts by their teachers. Some of the students were however able to provide solution paths that showed that they conceptually understood proportional reasoning. As shown by the data, a grade 6 student was able to use drawing to solve the problem; a grade 7 student was able to use table to solve the problem; and a grade 8 student was able to use words and analysis to show understanding. This finding indicate, just like the quantitative data, that children already have the mathematical sense of proportional reasoning in their schema prior to formal instruction. This finding begs to differ with Perry [22] who opined that only instruction affect learning and transfer.

In addition, and as mentioned earlier, the work of an $8^{\text {th }}$ grade student on the entire test shows how he used algebraic symbols and manipulation to arrive at the decimal, percent, ratio, and proportion problems. This is novel and shows that there is understanding of proportional reasoning and the related concepts by students in the study.

On the flip side, the data revealed that gaps also exist in the knowledge of proportional reasoning and the related concepts examined in the study. First, the quantitative data shows that the performance of students in all grade levels was not stellar in the test. As mentioned earlier, the grade 8 mean performance for the proportional reasoning problem was a mere 2.69 (maximum $=4)$. This could be considered low considering the fact that this concept has been taught to them. As a matter of fact there were mean performance scores that were much lower. For example, the grade 7 students had a mean score of 1.93 on the percent problem. 
They have also received instruction on that concept. The point here is that not every student in all grade levels did well. Also, the qualitative data revealed something else - students were not able to account for connections between and among concepts of decimal, percent, ratio, proportion, and proportional reasoning. For example, the grade 8 student could not fathom how decimal and percent or ratio and proportion are related, especially in the context of the problems presented in the study.

A possible reason for the gap may not be unconnected with the way topics are sequenced by teachers during instruction. Majority of teachers and their teaching practices would often not present the opportunity for students to see the big picture and the interconnectedness among mathematics concepts. The importance of big picture in mathematics teaching and learning cannot be overemphasized. As Randall [23] pointed out, "When one understands big ideas, mathematics is no longer seen as a set of disconnected concepts, skills or facts. Rather, mathematics becomes a coherent set of ideas." This is in line with Herbert, et al [24] who opined that "We understand something if we see how it is related or connected to other things we know." (p. 4). Whenever possible, mathematics teachers should avoid teaching mathematics concepts/topics in isolation. They should always plan to make students see the big picture by making connection among ideas and revealing the relationships that exist among concepts.

The second research question concerns fathoming factors responsible for understandings and gaps revealed in the study. The teachers' interviews revealed that those factors relating to the learner (learner variable) were remembering, forgetting, attitude towards mathematics, and motivation. The task variable factor was that of relating a task to specific real-life context. In other words, for the fact that the task was involving a real-life situation, the propensity for students to relate to it and get the problem right was enhanced. The strategy variable factors includes using effective problem strategy and the ability to apply previous knowledge to the present task. It needs to be mentioned that the interplay of learner variable, task variable, and strategy variable is necessary in accomplishing mathematics teaching and learning. Schunk [15] stressed the point that task, strategy, and learner variables typically interact when students engage in metacognitive activities.

In conclusion, the study revealed that understandings and gaps do exist in middle level grades in proportional reasoning and the related concepts of decimal, percent, and ratio. One implication of the findings of this study would be that teachers capitalize on the fact that children do have the schema for proportional reasoning even without being exposed to the concept through instruction. Teachers should rely on this information to plan instruction that would further enhance the concept by providing rewarding, enriching, and challenging learning activities and tasks for students. The study also revealed that students might not necessarily be able to do decimal, percent, and ratio quite well but are able to handle proportional reasoning problems. This was evident in the data where grades 6 and 7 students had higher mean scores in the proportional reasoning problem than they did on the percent and ratio problems. In view of this finding, teachers should not be hindered in planning higher level concepts just because they feel that students have not yet mastered a concept at the lower level. The final implication that arose from the study is that teachers should use multiple forms of assessment in their classrooms. It was evident that because students were made to solve a problem using a different strategy, they consequently were able to use novel and non-algorithmic methods. In view, observations and oral presentation should be seen as viable alternative methods of assessing students.

Future studies should consider an instructionally based research whereby teachers are observed as they engage in teaching practices. This will provide insights into the actual role played by instruction in the gaps and understandings analyses. Rather than self-report their methods of instruction as done in this study, future studies should scientifically investigate the teaching practices of teachers and showcase the effect of such practices on the concept of proportional reasoning.

\section{REFERENCES}

[1] National Council of Teachers of Mathematics. Curriculum and Evaluation Standards for School Mathematics. Reston, VA. NCTM. 1989.

[2] Common Core State Standards Initiative. Common Core State Standards for Mathematics. Washington, DC: National Governors Association Center for Best Practices and the Council of Chief State School Officers. 2010.

[3] Heinz, K., \& Sterba-Boatwright, B. The when and why of using proportions. Mathematics Teacher, 2008, 101(7), 528-533.

[4] Tourniaire, F. Proportions in elementary school. Educational Studies in Mathematics, 1986, 17, $401-412$.

[5] Hoffer, A. Ratios and proportional thinking. In T. Post (Ed.), Teaching Mathematics in Grades K - 8: Researched Based Methods. (pp. 285-313). Allyn \& Bacon. Boston, MA. 1988.

[6] Singh, P. Understanding the concepts of proportion and ratio among grade nine students in Malaysia. International Journal of Mathematical Education in Science and Technology, 2000, 31(4), 579-599.

[7] Ben-Chaim, D., Fey, J., Fitzgerald, W., Benedetto, C., \& Miller, J. Proportional reasoning among $7^{\text {th }}$ grade students with different curricular experiences. Educational Studies in Mathematics, 1998, 36, 247-273.

[8] Lo, J.J., \& Watanabe, T. Developing ratio and proportion schemes: A story of a fifth grader. Journal for Research in Mathematics Education, 1997, 28(2), 216-236.

[9] Lawton, C.A. Contextual factors affecting errors in proportional reasoning. Journal for Research in Mathematics Education, 1993, 24, 460-466. 
[10] Eggen, P., \& Kauchak, D. Educational psychology: Windows on classroom $\left(5^{\text {th }}\right.$ ed.). Merrill Prentice Hall. Upper Saddle River, NJ. 2001.

[11] Atkinson, R., \& Shiffrin, R. Human memory: A proposed system and its control processes. In K. Spence \& J. Spence (Eds.), The psychology of Learning and Motivation. Vol. 2. New York: Academic Press. 1968.

[12] Gagne, E. The psychology of school learning. Little, Brown \& Company. Boston, MA. 1985.

[13] Anderson, J. Cognitive psychology and its applications $\left(2^{\text {nd }}\right.$ ed.). New York: W.H. Freeman Company. 1985

[14] Duell, O.K. Metacognitive skills. In G.D. Phye \& T. Andre (Eds.), Cognitive classroom learning: Understanding, thinking, and problem solving (pp. 205-242). Orlando. Academic Press. 1986.

[15] Schunk, D. Learning theories: An educational perspective $\left(4^{\text {th }}\right.$ ed). Pearson Merrill Prentice Hall. Upper Saddle River, NJ. 2004.

[16] Flavell, J.H. Cognitive development (2 ${ }^{\text {nd }}$ ed.). Englewood Cliffs, NJ: Prentice Hall. 1985.

[17] Gay, L.R., Mills, G.E., \& Airasian, P. Educational research: Competences for analysis and applications. Pearson. Boston,
MA. 2012.

[18] Creswell, J.W. Educational research: Planning, conducting, and evaluating, quantitative and qualitative research. Pearson. Boston, MA. 2012.

[19] Powell, S.D. Introduction to middle school ( $2^{\text {nd }}$ ed). Pearson. Boston, MA. 2011.

[20] Schorn, A.C. Proportional reasoning by young children. Unpublished master's thesis, Cornell University, Ithaca, NY. 1989.

[21] Van den Brink, J., \& Streefland, L. Young children (6-8) ratio and proportion. Educational Studies in Mathematics, $1979,10,403-420$

[22] Perry, M. Learning and transfer: Instructional conditions and conceptual change. Cognitive Development, 1991, 6, 449-468.

[23] Randall, CC. Big ideas and understandings as a foundation for elementary and middle school mathematics. Journal of Mathematics Education Leadership, 2005, 7(3), 9-24.

[24] Hiebert, J., Carpenter, T.P., Fennema, E., Fuson, K., Werane, D., Murray, H., Olivier, A., \& Human, P. Making sense: Teaching and learning mathematics with understanding. Heinemann. Portsmouth, NH. 1997. 